\title{
PROYECTOS Y ENSAYOS EN TORNO A LA PRIMERA EXPOSICIÓN CONJUNTA DE ARTE NORMATIVO ESPAÑOL
}

\author{
POR \\ PAULA BARREIRO LÓPEZ \\ Departamento de Historia del Arte, CSIC
}

La Primera Exposición Conjunta de Arte Normativo Español, realizada en el Ateneo de Valencia en marzo de 1960, fue el resultado de toda una serie de proyectos anteriores que, desde 1959, estaban encaminados a la unificación de las tendencias constructivistas españolas en un frente común. El objeto de este artículo es el estudio de dichos proyectos precedentes y de su transformación en la citada exposición, analizando, además, los planes y debates que suscitó la muestra, tanto dentro del colectivo, como en la crítica del momento.

Palabras clave: Arte normativo. Constructivismo. s. XX. Vicente Aguilera Cerni. Equipo 57. Grupo Parpalló-Equipo Córdoba. Manuel Calvo. José María de Labra

The Primera Exposición Conjunta de Arte Normativo Español, held in the Athenaeum of Valencia in March 1960, was the result of a series of earlier projects which, since 1959, had been oriented toward the unification in a common front of Spanish constructivist tendencies. In this article the author studies the precedent projects and their transformation into this exhibition, and analyses the projects and debates brought about by the show, both within this collective and in the criticism of the period.

Key words: Normative art. Constructivism. 20th century. Vicente Aguilera Cerni. Equipo 57. Grupo Parpalló-Equipo Córdoba. Manuel Calvo. José María de Labra.

La implantación de la abstracción como tendencia de modernidad en España, discurrió, en la segunda mitad de los años cincuenta del siglo xx, desde el cauce de una doble opción artística: la abstracción informalista y la abstracción constructivista. Los esfuerzos por la creación de un frente constructivista no se discutieron hasta los inicios de la década de los sesenta, como veremos, pero ya desde los cincuenta diferentes artistas aportaron nuevas visiones plásticas sobre el estudio de la forma y la geometría. Jorge Oteiza, incansable en su empeño de difundir el análisis del espacio, fue una figura de referencia para los constructivistas españoles ${ }^{1}$. Ya

\footnotetext{
${ }^{1}$ Jorge Oteiza desarrolló, a lo largo de su carrera, una intensa labor artística e intelectual en torno a la estética objetiva. Ya en 1947, durante su estancia en Latinoamérica, creó en Perú el primer grupo «Espacio» de experimentación de pintores, escultores y arquitectos. A su vuelta a España, realizó toda una serie de obras encaminadas a continuar sus investigaciones espaciales, complementadas por textos y reflexiones, que el artista difundió a través de conferencias, libros y artículos. Además, en el año 1954, gracias a un viaje a Córdoba por motivos de trabajo, entró en contacto con un grupo de
} 
desde París, centro de encuentro y reunión de multitud de artistas españoles, otras personalidades inauguraron su carrera dentro de las tendencias racionales, con un barniz internacionalista: Pablo Palazuelo, Eusebio Sempere, Ángel Duarte, Agustín Ibarrola, etc. A los impulsos individuales de estos artistas se unieron dos agrupaciones fundamentales para la posterior travesía de las tendencias constructivistas españolas y, más concretamente, para lo que se denominó arte normativo español. Estos fueron el Grupo Parpalló ${ }^{2}$ y el Equipo $57^{3}$.

La presencia de una vertiente constructivista en España, muy desperdigada e inconexa en sus primeros años de gestación, fue jalonando sus esfuerzos para el desarrollo de un frente analítico, desde el año 1957, hasta los albores del año 1961, con la organización del movimiento de arte normativo y la realización de su única manifestación plástica: la Primera Exposición Conjunta de Arte Normativo Español.

Desde el año 1959 los intereses racionalistas y la identificación estilística entre los artistas, contribuyeron a la agrupación de los representantes de esta tendencia, que coincidieron en las diversas actividades promovidas por los grupos más activos. Unas iniciativas, que si bien contaron con el empuje de artistas como el Equipo 57, Manuel Calvo, Jorge Oteiza, también tuvieron el apoyo férreo de un sector determinado de la crítica, representado por Vicente Aguilera Cerni, Antonio Giménez Pericás y José María Moreno Galván. Los intentos de organización de la Bienal de San Sebastián ${ }^{4}$, los coloquios en torno al arte abstracto ${ }^{5}$, que surgieron a la par que las primeras exposiciones de arte concreto, los manifiestos y declaraciones de artistas como los del Equipo 57, Parpalló, Manuel Calvo o la incansable actividad del crítico Vi-

artistas cordobeses (José Duarte, Francisco Aguilera Amate, Juan Serrano y Luis Aguilera Bernier) que, tras su paso por la ciudad, decidieron comenzar a trabajar en equipo y crearon un nuevo grupo «Espacio» que, como destaca Llorente, «aunque no hizo obra debe considerarse uno de los precedentes del Equipo 57» (Llorente, Ángel, Equipo 57, Córdoba, Diputación de Córdoba, 2003, p. 14). Sobre Oteiza véase Oteiza. Propósito experimental, Madrid, Fundación Caja de Pensiones, 5 febrero-20 marzo, 1988.

${ }^{2}$ El grupo Parpalló se formó en Valencia en octubre de 1956. Al colectivo perteneció una gran plantilla de artistas valencianos que fueron modificándose a lo largo de su trayectoria, sin embargo desde 1959 la nómina de artistas quedó determinada a Vicente Aguilera Cerni, Antonio Giménez Pericás, Andreu Alfaro, Eusebio Sempere, Monjalés, Isidoro Balaguer y Martínez Perís. Las actividades de Parpalló se centraron en la búsqueda de la revitalización del panorama artístico valenciano, organizando exposiciones, coloquios, editando la revista Arte Vivo, etc. Entre sus filas no existió una tendencia estética común, sino que sus representantes se posicionaron en torno a las dos vertientes de la abstracción: el informalismo y el constructivismo. Su labor se desarrolló desde el año 1956 hasta 1961, dejando como testimonio póstumo la exposición de Polonia de 1965. (Véase Ramírez, Pablo, El grupo Parpalló. Construcción de una vanguardia, Valencia, Institució Alfons el Mágnánim, 2000).

${ }^{3}$ El Equipo 57 se fundó en París en 1957, fecha en la cual realizó su primera exposición en el Café Rond-Point de Montparnasse y redactó su primer manifiesto. Los integrantes del Equipo aunque contaron con la presencia puntual de otros artistas en sus primeros momentos, fueron José Duarte, Agustín Ibarrola, Ángel Duart, Juan Serrano y Juan Cuenca. Estos organizaron su trabajo en torno a dos puntos geográficos fundamentales: Córdoba y París. Su actividad pictórica en rigurosa colectividad, se complementó con una intensa actividad teórica que dio a la luz un número importante de escritos y manifiestos en torno a la interactividad del espacio plástico, el carácter social del arte abstracto y la estética objetiva. Su trayectoria terminó en los albores de 1962, aunque no fue hasta 1965 cuando, de manera oficial, declararon el final de su colaboración con una exposición retrospectiva en la Galería d’Art Actuelle de Ginebra. (Véase Llorente, Ángel, Equipo 57, Op. Cit., 2003).

${ }^{4}$ En los proyectos para la Bienal de San Sebastián de 1959, Jorge Oteiza y Eduardo Chillida tuvieron un papel muy destacado. Dentro de sus propuestas se encontraba la realización de una gran exposición de arte constructivo que aunara escultura, pintura, arquitectura y diseño industrial, en donde dar cabida a las tendencias racionales emergentes. Esta iniciati$\mathrm{va}$, vista con gran interés desde las filas constructivistas, iba a reunir a aquellos interesados por las tendencias formales, contando con Aguilera Cerni dentro del Comité Directivo. Sin embargo, por problemas de entendimiento entre el colectivo de artistas y los intereses del Ayuntamiento, la Bienal acabó por ser suspendida (Correspondencia entre Jorge Oteiza y Vicente Aguilera Cerni, diciembre 1959, Centro Internacional de Documentación Artística, Vilafamés).

${ }^{5}$ En 1959 se organizaron, en la Sala Darro de Madrid, los coloquios Primera Decena de Problemas Estéticos Actuales; en el mismo año, con ocasión de la exposición de Manuel Calvo en el Club Universitario de Valencia, se realizaron unas conferencias sobre la problemática del arte contemporáneo. En ambas citas coincidieron un gran número de aquellos que, meses después, estarán implicados en el movimiento de arte normativo: el Equipo 57, Pericás, José María Moreno Galván y Aguilera Cerni (Véase Arte Vivo. Suplemento de informaciones artísticas y bibliográficas, Valencia, mayo-junio, 1959 , p. 1)

AEA, LXXVIII, 2005, 310, pp. 163 a 174 
cente Aguilera Cerni, que desde Valencia, reflexionaba sobre la necesidad del trabajo en común y el carácter social del arte del momento ${ }^{6}$, propiciaron un clima de reflexión y debate en torno a las tendencias constructivistas y su papel en la sociedad española de finales de los cincuenta y principios de los sesenta.

Este caldo de cultivo dio sus frutos en la Primera Exposición Conjunta de Arte Normativo Español, en Marzo de 1960, que aglutinó a algunos de los principales representantes de las corrientes racionales, en torno a un nuevo movimiento artístico: el arte normativo. Sin embargo, las expectativas iniciales tuvieron un listón más elevado, siendo esta la modesta conclusión a un aluvión de proyectos e ideas mucho más ambiciosos, encaminados a procurar el despegue de las tendencias constructivas en colectividad, dentro y fuera del panorama nacional, por medio de exposiciones, publicaciones y todo tipo de manifestaciones ärtísticas. Estos proyectos se organizaron, fundamentalmente, a través del Grupo Parpalló y de la mano rectora de Aguilera Cerni, Giménez Pericás y Moreno Galván, los cuales unificaron los esfuerzos para poner en contacto a los diferentes artistas interesados en el arte constructivo, con el fin de propiciar el clima de intercambio, de entendimiento y de reflexión adecuado, que condujera a la creación de un frente común racionalista, alternativo a la generalidad informalista que durante estos años se estaba viviendo.

Podemos constatar, a través de la correspondencia privada del Grupo Parpalló, que, ya desde finales del año 1959, la intención de agrupar las tendencias formales españolas en una gran exposición era tema de debate en el enclave valenciano. De hecho, en estas fechas, Giménez Pericás comunicaba en una carta personal a Aguilera Cerni la apertura de las conversaciones con Calvo y el Equipo 57, para realizar la exposición conjunta de todo el arte constructivo español, puesto que «interesan en España todo planteamiento de [...] actitudes radicalmente comunitarias». El proyecto se encontraba en su fase inicial, contando con ideas todavía bastante imprecisas sobre el lugar, fecha y concurrentes a la cita. Así, «la exposición sería en Madrid-París, para la próxima primavera» ${ }^{7}$, con posibilidades de ampliarla a Italia, siempre que Aguilera pudiera aportar sus preciados contactos en dicho país — después de todo era él quien mantenía una estrecha relación con Giulio Carlo Argán ${ }^{8}-$. En cuanto a los artistas, en estos momentos Pericás propone todo el batiburrillo de representantes de la abstracción geométrica española: Parpalló, Equipo 57, Oteiza, Basterrechea, Chirino, Labra, Benet, Calvo, $\mathrm{y}$ aquellos otros que pudieran ir surgiendo.

Como se manifiesta en la documentación, ya desde los inicios, el papel de la crítica, en la proyección y desarrollo del proyecto, fue determinante. Sus intereses principales se dirigían hacia la materialización de sus reflexiones teóricas en torno a la estética concreta y al arte social, a través de una gran exposición. Así, no es de extrañar que Pericás confirmara a Aguilera la iniciación de los trámites para la realización de «nuestra idea de una exposición colectiva de todo el constructivismo español», añadiendo que la «Exposición sería «Exposición de la Crítica» -la crítica somos nosotros tres» ${ }^{9}$.

\footnotetext{
${ }^{6}$ Desde 1959 Vicente Aguilera Cerni se interesó por la problemática y la necesidad de un arte social en España. Estas ideas las expuso en diferentes textos, entre los cuales, el más paradigmático fue «El arte además» (Índice de las artes y las letras, $\mathrm{n}^{\circ}$ 122-129, Madrid, de febrero a septiembre, 1959), en el cual se resumen la visión ética y moral del arte valenciano, que configurará, un año más tarde las reflexiones específicas sobre el arte normativo.

${ }^{7}$ Carta de Antonio Giménez Pericás a Vicente Aguilera Cerni, s/f, aunque probablemente es de finales de 1959. Archivo Privado Alfaro (a partir de ahora APAA), correspondencia.

${ }^{8}$ La relación entre Aguilera y Argán se estableció en la Bienal de Venecia del 1959, en donde el Tribunal, presidido por el propio Argán, otorgó el Gran Premio de la Crítica a Vicente Aguilera Cerni, tal y como nos ha comentado el propio Aguilera Cerni durante una entrevista, realizada en Valencia, el 24 de Junio de 2003. A partir de ese año, afianzará los lazos con Argán, convirtiéndose en el principal difusor, en España, de la ideología del italiano.

${ }^{9}$ Carta de Antonio Giménez Pericás a Vicente Aguilera Cerni, s/f, aunque probablemente es de finales de 1959. APAA, correspondencia.
} 
Frente a estos primeros proyectos, un tanto inespecíficos, los planes para la exposición se concretaron en pocos meses. La fecha se mantenía en la primavera de 1960 y los artistas se organizaban en tres apartados: escultores - «Oteiza, Chirino, Alfaro, Equipo 57, Serrano?, Subirachs?, Benavente, Calvo»-, pintores — «Equipo 57, Monjalés, Alfaro, Sempere, Calvo, Labra, Basterrechea, Benet, De la Sota?, Palazuelo, Grup. Córdoba, Equipo Forma, Vila-Casas?, Monzón»- y, «arquitectores» — «Equipo 57, Equipo Forma, Candela» ${ }^{10}$.

Las previsiones sobre los espacios expositivos seguían siendo los mismos, pero en esta ocasión, se añadía una información adicional: el posible emplazamiento concreto de la muestra en España. Así, la «Exp. sería en Madrid (DARRO?) París (los gestionará el Equipo 57) y Venecia (lo tratará Vicente, paralelamente a celebrar durante la Bienal)» ${ }^{11}$. En esos momentos, la Sala Darro parecía ser la opción más factible, dado el puesto de director que ostentaba Moreno Galván en dicha galería. La muestra pretendía adecuarse a los espacios más viables, barajando la doble posibilidad entre París y Milán, por el estrecho contacto que tenían con el entramado cultural de la capital francesa el Equipo 57 o Sempere ${ }^{12}$ y con Italia, Vicente Aguilera Cerni.

Por último, se detallaba hasta el catálogo, que dado el talante internacionalista que se le pretendía dar al movimiento, «podría ser un libro bilingüe y tricéfalo (escrito por los tres) escribía Pericás- al que le adjuntaría la forma normal de catálogo "industrial"»"13.

A lo largo de enero de 1960, la correspondencia, principalmente entre Giménez Pericás y el Grupo Parpalló, alude a los avances de la exposición, siendo el 13 de enero de 1960 la fecha definitiva para mandar «a todos nuestros formales» una carta de invitación — con membrete de Darro- para la exposición de arte constructivo. En ella se encuentran los datos ya concretos de lo que pretendía ser esta ambiciosa iniciativa. Se confirma la voluntarista actitud internacional de la crítica en esta empresa, dejando en evidencia, una vez más, su mano rectora en todo el proyecto. Así, dice la circular, en «una reunión que hemos mantenido recientemente Antonio Pericás, Vicente Aguilera Cerni y José María Moreno Galván, hemos llegado a la conclusión de lo necesario que se hace en las actuales circunstancias hacer público, tanto a la estimativa española de las artes como a la internacional, el estado actual de la abstracción formal. Como es evidente, el público está prácticamente percatado [que] de lo que se llama arte abstracto es el que está más o menos mediatizado por el informalismo. Situación que urge rectificar» ${ }^{14}$.

Tras el preámbulo de declaración de intenciones, se comentan claramente los detalles técnicos de la exposición. El emplazamiento de la misma discurriría entre Madrid (Sala Darro), seguramente París (Galería Denise René) y Milán (a través de Umbro Apollonio). La fecha se establecía en el mes de abril de 1960, con lo cual los artistas debían enviar sus obras — «con un máximo de cinco y un mínimo de dos»- a la Sala Darro antes del 20 de marzo. Y la lista de participantes se reducía al Equipo 57, Parpalló, Grupo Córdoba, Grupo Espacio, Néstor Basterrechea, José María de Labra, Manuel Calvo, Pablo Palazuelo, Jesús de la Sota, Manuel Benet, Jorge Oteiza, Martín Chirino, Pablo Serrano y José Luis Alonso.

\footnotetext{
${ }^{10}$ Carta de Giménez Pericás a Parpalló, s/f, posiblemente de finales de 1959 o principios de 1960. APAA, correspondencia.

${ }^{11}$ Idem.

${ }^{12} \mathrm{La}$ estancia en París del Equipo 57 y de Eusebio Sempere propició contactos directos con los artistas, marchantes y galerías más importantes para la difusión y exportación del arte constructivo en París. Principalmente, los intereses se dirigieron hacia la Galería Denise René, que ya había expuesto obra de estos artistas, entendiéndose por el colectivo normativo como el emplazamiento idóneo para comenzar el periplo artístico internacional.

${ }^{13}$ Carta de Giménez Pericás a Parpalló, s/f, posiblemente de finales de 1959 o principios de 1960. APAA, correspondencia.

${ }^{14}$ Circular firmada por Moreno Galván y Giménez Pericás, fechada en Madrid el 13 enero de 1960. APAA, correspondencia. Citada también por Martín Martínez, José, La escultura de Andreu Alfaro. Biografía artística y catálogo razonado, Valencia, Servicio de Publicaciones de la Universidad de Valencia, 1994.
}

$A E A$, LXXVIII, 2005, 310, pp. 163 a 174 
A pesar de existir un proyecto previo, la muestra no se pudo llevar adelante desde los primeros momentos, por la clara desunión entre las partes. Las cartas de invitación parece que no llegaron a enviarse, los protagonistas no estaban del todo de acuerdo con la iniciativa y los artistas se encontraban totalmente desinformados. Desde sus comienzos no se logró un acuerdo, ni siquiera desde los organizadores, puesto que mientras Aguilera y Pericás apostaban fuerte por la iniciativa desde Valencia, Moreno Galván la encontraba prematura y falta de organización ${ }^{15}$.

Las noticias del gran periplo del arte formal español se cortan aquí y la correspondencia enlaza, con naturalidad, con una nueva exposición que tendrá como sede el Ateneo de Valencia, en el periodo de fallas. Estos nuevos cambios, nos hacen ya considerar que se trata de la Primera Exposición Conjunta de Arte Normativo Español, organizada por el Grupo Parpalló entre el 12 y el 25 de marzo en la Sala de Exposiciones del Ateneo Mercantil de Valencia. Las expectativas de esta exposición fueron grandes, aunque ya desde sus comienzos, como declaró, años más tarde, Aguilera Cerni, «el «movimiento» había fracasado a las primeras de cambio, pese a los buenos propósitos y a la indudable buena fe de todos» ${ }^{16}$, por la evidente desconexión entre artistas y crítica.

El cambio de talante de esta iniciativa, con respecto a los proyectos anteriores, resulta evidente. En primer lugar, la larga nómina de artistas se oficializa en Parpalló, Equipo 57, Equipo Córdoba, José María de Labra y Manuel Calvo. Y, en segundo, se descarta la agrupación del grueso del arte constructivo, reorganizando la exposición en torno a una nueva denominación: arte normativo. Dicha designación recuperaba el término de nuevo cuño: normativismo, establecido por Aguilera Cerni ${ }^{17}$ dentro del activismo teórico en pro de la organización de las tendencias formales, que se estaba fraguando, desde finales de los cincuenta, por este crítico valenciano, Antonio Giménez Pericás y José María Moreno Galván. El nuevo término fue aceptado sin reservas por estos dos últimos, que reorganizaron las reivindicaciones, hasta entonces elaboradas en torno al arte concreto y analítico, alrededor de esta reciente denominación. Sin embargo, el nuevo movimiento de arte normativo, fue transformando las iniciales ansias de revitalización de la generalidad de la vanguardia constructivista, por la configuración de un programa específico y particular.

La organización de la exposición, tal como se especificaba en el catálogo, fue gestionada desde el Grupo Parpalló, partiendo del afán particular que surgía desde el sector crítico, representado por Antonio Giménez Pericás y, sobre todo, Vicente Aguilera Cerni —encargado de la búsqueda del espacio, la difusión de las invitaciones, la recepción de obras, la distribución de los artistas invitados en distintos alojamientos en Valencia, etc.-. La colaboración del resto de los asistentes en la iniciativa se centró, prácticamente, en el envío de las obras a la exhibición.

Esta exposición fue el primer contacto real entre los que integrarán, a partir de entonces y durante un breve periodo de tiempo, el normativismo. Así, la verdadera cooperación de los diversos participantes en el movimiento normativo se produjo, no sin ciertos recelos, durante los debates y los coloquios que surgieron en el enclave valenciano, a la par de la realización de dicha exhibición.

\footnotetext{
${ }^{15}$ Carta interna del Equipo 57, fechada en Madrid el 2 de febrero de 1960. Archivo Privado del Equipo 57 (a partir de ahora APE57), Córdoba, correo interno.

${ }^{16}$ Aguilera Cerni, Vicente, Panorama del nuevo arte español, Madrid, Guadarrama, 1966, p. 217.

${ }^{17}$ El término de normativismo salió a la palestra en el año 1960 y fue definido, por Aguilera Cerni, como «aquel que se produce, en función de la intencionalidad, como deber moral y servicio al bien. Es un arte para el que cuentan todos los problemas humanos, para el que es decisivo el orden de prioridad de sus urgencias. En su mismo origen se plantea como actividad humana para el hombre, como servicio y colaboración; admite la posibilidad de sacrificar lo espectacular a la eficacia ontológica, pues servir a la vida es cooperar a la plenitud del ser mientras le dura esa única oportunidad que es la existencia» (Aguilera Cerni, Vicente, «Arte normativo español. Primera pancarta para un movimiento», Cuadernos de arte y pensamiento, $\mathrm{n}^{\circ} 4$, Madrid, noviembre 1960, p. 52).
} 
La exposición contó con un catálogo [Fig. 1] en el que se reproducen diez de las obras presentadas, junto con un extenso texto de Antonio Giménez Pericás ${ }^{18}$, a favor de la colectivización del trabajo artístico. Por parte de Parpalló - según las reproducciones conservadas en el catálogo-, se presentó obra tanto colectiva como individual. Así, se expuso una pintura de Monjalés, otra de Balaguer, una escultura Alfaro, un relieve luminoso Sempere ${ }^{19}$ y el diseño del bar del Ateneo de Martínez Perís. El grueso de la obra de Parpalló no fue realizada ex profeso para la exposición, sino que, como afirma Pablo Ramírez, las obras habían sido expuestas en exposiciones precedentes ${ }^{20}$. Con todo, la aportación resumía los intereses artísticos de Parpalló, presentando una selección heterogénea en la que, las pinturas de Monjalés y Balaguer, contrastaban con el talante geométrico del resto de participantes. Junto a estas obras, Parpalló presentó, como obra colectiva, el fotomontaje Proyecto para un monumento al Mediterráneo ${ }^{21}$, que hace sospechar a Ramírez el posible «intento de Parpalló de ponerse oportunistamente a la altura de las circunstancias, al ofrecer al mismo tiempo una imagen artística individual del trabajo de cada uno de sus miembros, imagen que sí correspondía a la realidad, junto con otra imagen colectiva, que era totalmente ficticia» ${ }^{22}$.

El catálogo recoge, igualmente, una pintura del Equipo 57, donde plasma claramente su teoría de la interactividad plástica, una pintura del Equipo Córdoba muy en la línea de sus colegas cordobeses, una pintura de José María de Labra y, por último, otra de Manuel Calvo.

En lo que respecta al Equipo 57, sabemos que presentaron, además del lienzo reproducido en el catálogo, dos obras más de gran formato - cuyas medidas eran: $162 \times 114 \mathrm{~cm}, 116 \times 89$ $\mathrm{cm}, 100 \times 81 \mathrm{~cm}$ - realizadas para la exposición, debido a la carencia de cuadros en España. Si bien la obra del catálogo no la hemos podido localizar, las otras dos posiblemente formaran parte de la selección presentada en la exposición de Darro ${ }^{23}$ en el mes de mayo de 1960, puesto que dos de ellas coinciden en medidas y fecha. En el mismo paquete se enviaron otras tres obras de su homólogo, el Equipo Córdoba, que mantenía un tamaño standard de $133 \times 108 \mathrm{~cm}^{24}$.

A la luz de la documentación consultada, podemos constatar que el envío de las pinturas a Valencia supuso un verdadero problema para el Equipo 57 por la escasez de tiempo con el que contaron, puesto que no tuvieron constancia de la invitación formal hasta pasado el 7 de marzo de $1960^{25} \mathrm{y}$, si tenemos en cuenta que el 12 de marzo se inauguraba, es evidente que las obras debieron tener que hacerlas muy rápidamente. Por ello, no es de extrañar que, a la llega-

\footnotetext{
${ }^{18}$ Giménez Pericás, Antonio, «La estética lessigniana...», Primera Exposición Conjunta de Arte Normativo Español, Valencia, Ateneo Mercantil, 12-25 marzo, 1960, s/p.

${ }^{19}$ A pesar de la presencia de esta obra en el catálogo, la correspondencia de Sempere con sus compañeros de Parpalló nos ofrece una información totalmente distinta. Así, escribe «lamento no poder enviar el relieve porque un día de estos se lo llevarán seguramente un americano para una exposición; así que no tendréis mas remedio que exponer los gouaches que tenéis en Barcelona» (Carta de Eusebio Sempere a Andreu Alfaro, fechada en Madrid el 4 de marzo de 1960. APAA, correspondencia).

${ }^{20}$ Ramírez, Pablo, El grupo Parpalló... Op. cit., 2000, p. 148.

${ }^{21}$ En realidad, el fotomontaje estaba realizado por Alfaro, junto con los arquitectos Navarro, Gastaldi y García Matarredona, como se dice en el catálogo. Se trata de una de las pocas obras donde colaboraron estos arquitectos.

${ }^{22}$ Ramírez, Pablo, El grupo Parpalló..., Op. cit. 2000, p. 148.

${ }_{23}$ Véase Equipo 57, Madrid, Museo Nacional Centro de Arte Reina Sofía, 14 septiembre-8 noviembre, 1993, pp. 103, 106.

${ }^{24}$ Debido a la ausencia de documentación no sabemos con certeza el número de obras presentadas por cada representante, excepto, claro está, aquellas reproducidas en el catálogo. En base al conjunto de tres enviado por el Equipo 57 y el Equipo Córdoba y según la invitación de la exposición prevista para Darro, es posible que el número de obras establecido fuera entre dos y cinco. De Calvo y Labra sólo podemos saber que mandaron conjuntamente sus cuadros desde Madrid, el 5 de marzo de 1960, y ello gracias a una carta de Manuel Calvo a Aguilera Cerni, fechada en Madrid el 3 de marzo de 1960, en la que le confirma el envío de las obras de ambos en los próximos días (APAA, correspondencia).

${ }_{25}$ Sabemos de este hecho por una carta interna del Equipo 57, fechada en París el 7 de marzo de 1960, en la cual se informan de la invitación a dicha exposición. Archivo Privado Equipo 57 (a partir de ahora APE57), correo interno.
}

AEA, LXXVIII, 2005, 310, pp. 163 a 174 




Fig. 1. Catálogo de la Primera Exposición de Arte Normativo Español (Fotografía de la Biblioteca Nacional, Madrid). 
da a su lugar de destino, las pinturas se encontraran todavía frescas: «probablemente [los cuadros] - comentaban en la carta adjunta al envío de obra - llegarán frescos, han sido realizados estos últimos días. Cuando nos notificaron la celebración de esta exposición no disponíamos de cuadros al óleo en España, ya que todo el trabajo ultimo lo tenemos en gouaches de pequeño formato sin pasar todavía a materia más definitiva» ${ }^{26}$.

La premura de la exposición no sólo sorprendió al Equipo, sino que el propio Sempere, comentaba a su amigo y compañero Alfaro: «Qué ha sido hacer tan precipitadamente la exposición en Valencia? No acabo de comprenderlo» ${ }^{27}$.

Estas declaraciones ponen en evidencia el carácter, casi fortuito, de esta exposición. Tras los fracasos anteriores, Parpalló, no podía dejar pasar la oportunidad de una cita que se estaba dilatando demasiado en el tiempo, aprovechando al vuelo esta ocasión de exposición, en el único espacio que parecía favorable a la realización de la misma: el Ateneo de Valencia. Lugar con el que Parpalló y, sobre todo, Aguilera Cerni tenían una relación estrecha ${ }^{28}$.

Las reseñas de la exposición se redujeron a unas notas repartidas por los periódicos locales Levante y Las Provincias ${ }^{29}$ y las revistas Serra d'Or ${ }^{30}$ y Acento Cultural ${ }^{31}$-en la cual trabajaba Giménez Pericás-, pasando, en general, bastante desapercibidas dentro del panorama nacional. Sin embargo, a título local, el periódico Levante prestó una mayor atención al evento, publicando una entrevista de Sánchez Gijón a Aguilera Cerni ${ }^{32}$ y un editorial de Sabino Alonso-Fueyo ${ }^{33}$ — director de Levante, directivo del Ateneo Mercantil, encargado de inaugurar la exhibición-. Este último, daba rienda suelta a su particular punto de vista de espectador, haciendo hincapié en el carácter moral del arte normativo y llegando a equiparar sus apuestas éticas con un arte religioso y de «inconfundible acento cristiano» ${ }^{34}$. En la entrevista, Aguilera Cerni, se mostraba contundente en sus declaraciones, ofreciéndonos interesantes informaciones sobre los aspectos que, ya entonces, determinaban al normativismo. Así, definía el arte normativo como un arte «con responsabilidad social»; reconocía el papel de la técnica «como el camino más directo para incorporar a la vida social las experiencias estéticas y enriquecer la sensibilidad colectiva» ${ }^{35}$; declaraba el propósito de coordinar el normativismo como movimiento nacional y, para sorpresa del entrevistador, ubicaba estas nuevas experiencias en línea directa con Velázquez, el constructivismo ruso, el neoplasticismo, Max Bill o la escuela de Ulm. A su vez, el texto del catálogo de Giménez Pericás, ahondaba en otro de los aspectos principales del movimiento: la conciencia colectiva en el arte y en la existencia humana. Tan sólo con estas dos publicaciones y a fecha de 12 de marzo de 1960, ya estaban resumidas las líneas generales de lo que iba a ser el programa ideológico y estético del arte normativo, de-

\footnotetext{
${ }^{26}$ Carta del Equipo 57 a Vicente Aguilera Cerni, marzo 1960. APE57, correo externo.

${ }^{27}$ Carta de Sempere a Andreu Alfaro, Madrid, 4 marzo 1960. APAA, correspondencia.

${ }^{28}$ No hay que olvidar que Aguilera Cerni tenía una personal relación con el Ateneo Mercantil de Valencia, puesto que era la sede de Instituto Iberoamericano de Cultura - filial a su vez del Instituto de Cultura Hispánica- y organismo directamente implicado en la creación del Grupo Parpalló. Esta cercanía propició la realización de la exposición, puesto que «había muy pocos sitios para exponer, en el Ateneo fue posible porque allí se encontraba el Instituto Iberoamericano» (Entrevista a Aguilera Cerni, Valencia, 24 de junio de 2003).

${ }^{29}$ «Actos culturales en el Ateneo Mercantil», Levante, Valencia, 12 marzo 1960, p. 5; «Inauguración de la exposición de pintura Arte Normativo Español», Levante, Valencia, 13 marzo, 1960; «Primera exposición conjunta de arte normativo español», Las Provincias, Valencia, martes 15 marzo, 1960, p. 16.

${ }^{30}$ «Noticiari. Artes Plàstiques», Serra d'Or, Barcelona, año II, $2^{\text {a }}$ época, marzo-abril, 1960, p. 53.

${ }^{31}$ Giménez Pericás, Antonio, «Exposiciones. En el Ateneo de Valencia», Acento Cultural, suplemento n 23-26, Madrid, 1960 , p. 6. La reseña es más jugosa, debido a la implicación directa del autor. Éste apela a la seriedad y rigurosidad del movimiento, advirtiendo al lector que: «no se trata de una mera cuestión terminológica, ni de una facha rebelde adoptada por la antitendencia; en este caso sería una declaración abierta contra el amplio campo de la abstracción informal».

${ }^{32}$ Sánchez Gijón, Antonio, «Arte con norma moral: Normativismo», Levante, Valencia, 12 marzo 1960, p. 5.

${ }^{33}$ Alonso-Fueyo, Sabino, «Artista: “Tú debes"», Levante, Valencia, 13 de marzo de 1960, p. 1.

${ }^{34}$ Idem.

${ }^{35}$ Sánchez Gijón, Antonio, «Arte con norma moral:...», Op. cit., 1960.
}

$A E A$, LXXVIII, 2005, 310, pp. 163 a 174 
mostrando una claridad teórica preexistente, que estaba directamente conectada con el activo papel de la crítica en la construcción de este movimiento.

La inauguración de la muestra valenciana insufló nuevas energías al colectivo normativo que, con más prudencia, dirigió sus miras al horizonte internacional, proyectando para el futuro, como declaraba Aguilera Cerni, una «exposición fuera de España y una publicación de cierta envergadura ${ }^{36}$.

Sin embargo, la realidad estuvo muy lejos de los planes del crítico valenciano. Los proyectos de exposición en el extranjero no pudieron llevarse a cabo, dada la perjudicial heterogeneidad plástica en el grupo. Lo que en España pasaba por una iniciativa de vanguardia, en la que artistas diversos se unían en un propósito común, en Europa se veía como una amalgama de individuos sin coherencia plástica. Un problema que había sido apuntado por Sempere, con aplastante claridad, al comenzar a realizar los trámites para llevar la exposición a París: «Con Denise René hablé ya algo de esta exposición, no sólo del Grupo sino de los constructivistas españoles, pero el inconveniente de las galerías de París es que la línea de cosas a exponer, es siempre muy determinada. Es decir, en algunas tachistas rabiosos, en otras menos, en otras cuadros un poco más construidos. Por ejemplo en Denise René sólo pueden exponer los exageradamente geométricos, por lo tanto no podrían exponer ni Monjalés ni Balaguer...» ${ }^{37}$.

Incluso los intentos de realizar otra exposición, en un espacio más emblemático para el arte español, tampoco llegaron a concretarse. A la par que organizaban, a marchas forzadas, la exposición del Ateneo, el colectivo normativo entraba en negociaciones con el director del $\mathrm{Mu}$ seo de Arte Contemporáneo de Madrid, con la intención de exponer en sus salas. Como comenta Pericás a Alfaro, «estamos en conversaciones con Chueca, el director del Museo de Arte Contemporáneo para que patrocine la Exposición de Arte Formal. En principio está de acuerdo ${ }^{38}$. Sin embargo, estas negociaciones, por motivos que desconocemos, no llegaron a materializarse y por segunda vez - recordemos el proyecto para la exposición de la Galería Denise René en el $57^{39}$ - el Museo de Arte Contemporáneo dejó pasar la ocasión de mostrar el repertorio del arte analítico contemporáneo.

Aunque la exposición de arte normativo no llegó a materializarse en todo su esplendor, la reunión de la mayoría de los expositores en el suelo valenciano, durante la misma ${ }^{40}$, propició un verdadero foro de debate, planes, líneas de acción y proyectos paralelos, para la unificación de los grupos de arte concreto en un frente común ${ }^{41}$. La Primera Exposición Conjunta de Arte Normativo Español se entendió, en realidad, como el punto de partida de toda una serie de acciones dirigidas a relanzar el arte concreto en España. De hecho, la idea fundamental que pla-

\footnotetext{
${ }^{36}$ Idem.

${ }^{37}$ Carta de Eusebio Sempere a Andreu Alfaro, fechada en Madrid el 4 de marzo de 1960. APAA, correspondencia.

${ }^{38}$ Carta de Antonio Giménez Pericás a Andreu Alfaro, sin fecha, probablemente de principios de 1960. APAA, correspondencia.

${ }^{39}$ A lo largo de 1957 se produjo un cruce de correspondencia entre Eusebio Sempere y Fernández del Amo (director del Museo de Arte Contemporáneo), con el fin de realizar una exposición de los artistas de la Galería Denise René a lo largo de ese año. Si bien en principio las partes parecían estar de acuerdo, finalmente, ante el desinterés del director, la exposición no llegó a realizarse. Fue una lástima, si tenemos en cuenta la temprana fecha del proyecto y los artistas que se estaban barajando: Arp, S. Tauber Arp, Magnelli, Herbin, Agam, Calder, Soto, Sempere, etc. (correspondencia entre Sempere y Fernández del Amo, julio-octubre 1957, Biblioteca del Museo Nacional Centro de Arte Reina Sofía, MATERIAL ESPECIAL 4978/4790).

${ }^{40}$ En Valencia se dieron cita Manuel Calvo, José María de Labra, Juan Cuenca (por parte del Equipo 57), los miembros de Parpalló y posiblemente, José María Moreno Galván.

${ }^{41}$ Estas conversaciones fueron destacadas en la breve reseña de la exposición de Giménez Pericás para Acento Cultural, diciendo: «En las conversaciones celebradas en Valencia, por artistas y críticos en esta ocasión, el arte normativo abrazaba los estilos formales y constructivistas que se pronuncian por el propósito ético del arte; por un lado proponiendo una estética ontológica y aconsejando el rigor formal con la intención de integrar al hombre en su espacio-tiempo de un modo consciente» (Giménez Pericás, Antonio, «Exposiciones», Acento Cultural, no 23-26, Madrid, Suplemento Quincenal, Madrid, 1961, p. 6).
} 
neó durante toda la muestra, fue la propuesta de Aguilera Cerni de creación de una federación de grupos de arte concreto. Una iniciativa que, a juzgar por la documentación consultada, era la recuperación de un proyecto anterior, ideado para llevarse a cabo en torno a la revista Arte Vivo ${ }^{42}$.

Desde el Equipo 57 no se veía con muy buenos ojos un apoyo abierto a las iniciativas valencianas y al exceso de protagonismo del Parpalló en detrimento suyo, por lo que prefería apostar por el cambio del centro neurálgico de las actividades normativas de Valencia a Madrid $^{43}$. Sin embargo, estos prejuicios, fueron abandonados rápidamente, cuando se realizó la exposición y se estableció el contacto entre los artistas del Equipo 57 y Aguilera Cerni, Pericás y Parpalló. La visita a Valencia les demostró un verdadero interés, por parte de los artistas y críticos valencianos, por la creación de esa federación y por el papel activo y fundamental del Equipo en dicha empresa ${ }^{44}$.

El encuentro entre los artistas, propiciado por la exposición, fue fructífero, inyectando nuevas fuerzas a la agrupación y a las actividades en torno a la difusión del arte normativo. Así, el 23 de marzo de 1960, se organizó una reunión en casa de José María de Labra, con Moreno Galván, Aguilera Cerni y miembros del Equipo, donde se retomaron los proyectos de difusión, organización y relanzamiento de las tendencias constructivistas españolas en los medios artísticos nacionales e internacionales, unas ideas ya discutidas en las reuniones realizadas en el Ateneo de Valencia durante la exposición. Las líneas rectoras de la actuación como colectivo, se centraron en varios puntos: en primer lugar, en la difusión y propaganda del movimiento, mediante «una campaña en las revistas españolas y extranjeras sobre el arte constructivo español», propuesta por Aguilera Cerni; y, en segundo, un intento de unificación de los artistas haciendo «un llamamiento por escrito a los pintores y arquitectos a fin de informar de lo que significaría un movimiento normativo. Explicando el objetivo y el porqué de normativo que parece que han aceptado todos» ${ }^{45}$. A pesar de que estas actividades tenían un cariz colectivo, lo cierto es que la crítica llevaba la voz cantante, y, sobre todo, la figura de Aguilera Cerni, que aglutinaba el papel de cabeza rectora del colectivo.

De estas maniobras de revitalización de las corrientes racionales, vieron la luz toda una serie de textos y reflexiones en torno al tema - muchas de las cuales, eran escritos realizados con anterioridad que, rápidamente, pasaron a formar parte del aparato teórico del normativismo-, que pretendían dar la dirección definitiva al movimiento. De este modo, surgieron en Acento Cultural, Claustro, Cuadernos de Arte y Pensamiento, principalmente, una batería de artículos de apoyo al normativismo, que si bien ahondaban en los aspectos fundamentales del mismo, demostraban también la falta de cohesión existente en las entrañas de la agrupación ${ }^{46}$. Sin em-

\footnotetext{
${ }^{42}$ Carta de Ángel Duart y Agustín Ibarrola al resto de miembros del Equipo 57, fechada en París el 7 de marzo de 1960. APE57, correo interno.

${ }^{43}$ Idem.

44 «Aguilera y Pericás están lanzados en este asunto y por parte de Parpalló, Alfaro. Todo lo que pretenden respecto a la federación comprenderéis no pueden hacerlo sin el equipo, y cuando se habla de arte normativo tienen que mirar al equipo» (carta interna del Equipo 57, fechada en Madrid el 22 de Marzo de 1960. APE57, correo interno).

${ }^{45}$ Carta interna del Equipo 57, fechada en Madrid el 24 de marzo de 1960. AE57, correo interno.

${ }^{46}$ Durante los años 1960-1961, tras la Primera Exposición Conjunta de Arte Normativo Español, fueron publicándose, en diversas revistas especializadas, toda una serie de artículos que reflexionaban sobre las nuevas aportaciones del arte normativo, con la intención de promover la difusión y el interés de estas tendencias en España como alternativa al arte informalista. Estas publicaciones encontraron un espacio abierto, sobre todo, en Acento Cultural, debido a la relación contractual que tenía con el crítico Antonio Giménez Pericás. Citamos aquí los más importantes: Aguilera Cerni, Vicente, «Arte normativo español. Primera pancarta para un movimiento», Cuadernos de arte y pensamiento, $\mathrm{n}^{\circ} 4$, Madrid, noviembre 1960, pp. 43-55. Calvo, Manuel, «Sobre la ilustración de este $\mathrm{n}^{\circ} 8$ en Acento», Acento Cultural, $\mathrm{n}^{\circ}$ 8, Madrid, mayojunio, 1960, pp. 54-55. Equipo Córdoba, «Proceso y concepción artística», Acento Cultural, n 8, Madrid, mayo-junio 1960, pp. 56-57. Equipo 57, «Idea y plan», Acento Cultural, n 8, Madrid, mayo-junio 1960, pp. 58-61; «Acerca de un panorama actual del arte en España», Acento Cultural, n 11, Madrid, abril 1961, pp. 54-56. Giménez Pericás, Antonio, «Propósito de coherencia y arte concreto», Acento Cultural, n 7, Madrid, marzo-abril, Madrid, 1960, pp. 41-45; «En Ateneo de Va-
}

$A E A$, LXXVIII, 2005, 310, pp. 163 a 174 
bargo, fue en el campo de la reflexión teórica donde el normativismo realizó sus aportaciones más interesantes, organizando, no sin cierta confusión, todo un programa teórico y estético en torno a la recuperación del carácter social del arte, la función del arte como transformador del entorno humano, a través de la pintura, la escultura, la arquitectura y el diseño.

Además de esta aluvión de escritos en el entorno nacional, lo cierto es que la difusión teórica del normativismo pretendía realizarse desde una plataforma más privilegiada. La creación de una revista propia, que divulgara las novedades del normativismo, era el siguiente paso previsto, tal como nos informa una breve nota en la revista Serra d'Or ${ }^{47}$.

Lamentablemente, esta intención, junto a las demás, no pudo llegar a buen puerto y, a pesar de los intentos de revitalización del movimiento, a través de la exposición de Valencia, tan sólo se consiguió una orquestación de publicaciones en torno al normativismo en determinadas revistas especializadas españolas, durante el año 1960 y parte de 1961, renunciando, claro está, a toda empresa internacional.

Sin embargo, a pesar de las prisas, del fracaso de la carrera internacional y de su limitada repercusión nacional, el normativismo no dejó indiferente a todo el panorama artístico español, recibiendo ciertas muestras de apoyo de algunos sectores críticos. Así, Carlos Antonio Areán declaraba su abierto interés por el arte constructivo y se planteaba la inclusión de sus propuestas en una publicación de cierta envergadura que tenía entre manos. Escribía, «a medida que pasa el tiempo, cuando recuerdo esas obras que al verlas no me conmovieron, siento a cada momento un abierto interés por ellas y por el constructivismo de los equipos de Córdoba. Mi preocupación por esta pintura de tipo apriorístico se ha hecho tan grande, a medida que he ido meditando en ella, que me he decidido a cambiar la distribución de capítulos de mi libro y a dedicar uno entero al constructivismo que el «Grupo Parpalló» y los equipos de Córdoba propugnan ${ }^{48}$. Valeriano Bozal, por su parte, se decidía a reflexionar en torno al tema del constructivismo en España con ecuanimidad ${ }^{49}$, intentando conciliar las que se entendieron, en un principio, como tendencias opuestas: el informalismo y el constructivismo. Y Alexandre Cirici Pellicer mostraba su apoyo, desde Serra d'Or, a la nueva visión colectiva y socialmente responsable del movimiento normativo diciendo: «l'interès de Vicent Aguilera, des de València, per un art normatiu, la creació de l'Institut del Disseny Industrial, són signes d'una virada profunda que pot fer de la nostra plàstica, eixida d l'organicisme i de l'informalisme, una palanca definitiva per al treball a favor de la veritat, la superatió, la solidaritat i l'orientació de l’homme cap a una finalitat realment inscrita en la història» ${ }^{50}$.

lencia», Acento Cultural, Suplemento Quincenal, no 3-4, Madrid, 1 abril, 1960, pp.41-45; «La estética de un arte sin objetos», Acento Cultural, $\mathrm{n}^{\circ}$ 8, Madrid, mayo-junio, 1960, pp.38-42; «La estética y su condicionamiento social», Práxis, $\mathrm{n}^{\circ} 3$, Córdoba, septiembre-octubre, 1960, s/p; «El arte normativo y la disolución de la pintura», Acento Cultural, $\mathrm{n}^{\circ}$ 31-34, Suplemento Quincenal, Madrid, 1961, pp. 1-4; «Despersonalización de arte y sociedad», Acento Cultural, $\mathrm{n}^{\circ} 11$, Madrid, abril, 1961, pp. 37-44. Moreno Galván, José María, «Discriminación apresurada de la abstracción en España», Acento Cultural, $\mathrm{n}^{\circ}$ 6, Madrid, enero-febrero, 1960, pp. 39-45; «La pintura «personal» de Manuel Calvo», Acento Cultural, $\mathrm{n}^{\circ}$ 7, marzo-abril, 1960, pp. 52-53; «Equipo 57», Acento Cultural, no 8, Madrid, mayo-junio, 1960, pp. 46-49; «Arte normativo. El normativismo no es un clasicismo», Acento Cultural, n ${ }^{\circ} 31-34$, Suplemento Quincenal, Madrid, Julio 1961, pp. 5-10.

47 «Noticiari. Artes Plàstiques», Serra d'Or, Op. cit., 1960, p. 53.

${ }^{48}$ Carta de Carlos Antonio Areán a Andreu Alfaro, fechada en Madrid el 15 de abril de 1960. APAA, correspondencia.

${ }^{49}$ Durante estas fechas, Valeriano Bozal escribió algunos artículos que ahondaban en esta nueva formación desde un aspecto más universal, valorando las dos categorías polares del arte contemporáneo: el arte de la razón y el arte del sentimiento. Bozal Fernández, Valeriano, «Situación del arte objetivo», Acento Cultural, nº 8, Madrid, mayo-junio, 1960; «Lo individual y lo universal en el arte contemporáneo», Acento Cultural, no extraordinario, Madrid, julio-octubre, 1960, pp. $71-73$.

${ }^{50}$ Cirici Pellicer, Alexandre, «Un nou esperit per la plàstica», Serra d'Or, $2^{a}$ época, año II, n 5, Barcelona, Mayo, 1960, pp. 26-28. Continua diciendo Cirici: «L'esperança d’un art que oposi una aportació positiva al nihilisme informalista, que siguiu normatiu i general enfrot de la gratuïdad anàrquica i particular, que sigui transcendent contra la pobresa immanet; que participi de la impersonalitat universal i necessària de la raó, per damunt la limitació i l'error perspectivista de les coses immediates; positiu enfrot de la negació, solitari enfrot de l'individualisme, se'ns fa albiradora en aquest tombant d'avui i de casa nostra».

$A E A$, LXXVIII, 2005, 310, pp. 163 a 174 
Como contrapartida, otros testimonios y análisis surgieron directamente en contra de esta nueva estética. Así, Juan Manuel Delgado, en el mismo mes de la exposición, publicaba un artículo en Claustro. Junto a la equiparación entre el arte constructivo y el clasicismo, la reducción de su estética a la traducción de los reflejos del alma del artista y los ataques directos a la teoría espacial del Equipo 57, aludía a la ineficacia de estas tendencias dentro del territorio español, por lo atípico de esta condición racionalista dentro de nuestro temperamento pasional latino: «Así, pues, el constructivismo no puede representar el pathos, el devenir y su actualización de muchos pueblos. Quedémonos con los latino-americanos. Es imposible encerrar al hombre hispanoamericano en un círculo mondrianesco, por muy sentimental que éste sea» ${ }^{51}$.

Paradójicamente, este comentario se encuadraba en un momento histórico en el que, la pauta de las tendencias racionalistas, comenzaban a darla un grupo importante de latinoamericanos residentes en París (Jesús Rafael Soto, Carlos Cruz-Díez, Julio Le Parc, Hugo Demarco, García-Rossi, Luis Tomasello, etc.).

Además de las críticas en torno a la problemática de un estilo constructivista en España, el debate se centró también en algunos intereses más destacados para el colectivo normativo: el estudio del espacio en la obra y su repercusión en el entorno del hombre. De este modo, Luis Trabazo, desde Índice de las Artes y las Letras, se sumaba al carro de la crítica y reflexionaba sobre la supuesta primacía del arte racionalista en el análisis y ejercicio de una visión espacial emparentada con la ciencia. Sus críticas arremetían contra la ingenuidad y pedantería de unas tendencias que se creían con pleno derecho de la primacía espacial, sin poseer demasiados conocimientos científicos sobre el tema. Decía, «muchos artistas y críticos de extrema vanguardia, ingenuamente beligerantes y no siempre bien enterados, promovieron no pocas, inútiles y aún peligrosas confusiones aireando sin ton ni son el espacio, como quien enarbola una bandera al viento, y repitiendo a menudo la palabra, sin que a ella correspondiera un riguroso concepto y conocimiento de las cosas» ${ }^{52}$.

Sin embargo, aunque durante los años 1960-1961 se logró actualizar el tema del normativismo, promoviendo el debate en torno a la recuperación del compromiso social y la responsabilidad ética, a través de una plástica objetiva; $y$, aunque durante un breve período de tiempo parecía que la unificación de las tendencias formales podía cuajar en un empeño común, la realidad se impuso sin piedad, demostrando que el final era la crónica de una muerte anunciada. La incomprensión del entorno artístico y social del momento, las dificultades de exposición y, sobre todo, las diferencias entre los protagonistas, convirtieron el gran proyecto de la normatividad en una entelequia. Así, lo que había comenzado como el intento más serio de configuración de un frente analítico en España, acabó reduciéndose a una exposición de provincias, que pasó con más pena que gloria por el panorama artístico del país. «El frente no llegó a fraguar nunca —opinaba Bozal-. El normativismo fue su manifestación más compleja pero de ningún modo homogénea o duradera» ${ }^{53}$. Por otro lado, el proyecto de una actividad artística normativa equiparable a la rica reflexión teórica, quedó en meras ilusiones, convirtiendo la posibilidad de una segunda exposición de arte normativo en un bosquejo inalcanzable. Y es que la desintegración del colectivo, sumada a la propia desaparición de los grupos de trabajo, se produjo en aras de una iniciativa más eficaz. Así, desde 1962, gran número de miembros de la agrupación normativa, pasándose al realismo, comenzarán su colaboración con Estampa Popular, con el fin de hacer valer, de una vez por todas, las premisas de compromiso social y responsabilidad ética.

\footnotetext{
${ }^{51}$ Delgado, Juan Manuel, «Comentario al arte constructivo», Claustro, $\mathrm{n}^{\circ}$ 12, Valencia, Marzo, 1960, s/p.

${ }^{52}$ Trabazo, Luis, «Problemas contemporáneos de Arte. Tiempo, espacio y vida», Índice de las Artes y las Letras, $\mathrm{n}^{\circ}{ }^{139}$, Madrid, julio, 1960, s/p.

${ }^{53}$ Bozal Fernández, Valeriano, «La razón en la imagen», Goya, nº 175-176, Madrid, julio-octubre, 1983, p. 41.
}

$A E A$, LXXVIII, 2005, 310, pp. 163 a 174 